\title{
Craniofacial Characteristics Related to Daytime Sleepiness Screened by the Paediatric Daytime Sleepiness Scale
}

\author{
Min $\mathrm{Gu}^{1}$, Yanqi Yang ${ }^{1,}$, Angus C.H. Ho ${ }^{2}$, Ricky W.K. Wong ${ }^{2}$, Urban Hägg ${ }^{3}$ and Colman P.J. \\ McGrath $^{4}$ \\ ${ }^{I}$ Department of Paediatric Dentistry and Orthodontics, Faculty of Dentistry, the University of Hong Kong, Hong Kong \\ SAR, China \\ ${ }^{2}$ Department of Dentistry and Maxillofacial Surgery Cleft Center (Craniofacial Orthodontics), United Christian Hospi- \\ tal, Hong Kong SAR, China \\ ${ }^{3}$ Faculty of Dentistry, The University of Hong Kong, Hong Kong SAR, China \\ ${ }^{4}$ Department of Dental Public Health, Faculty of Dentistry, The University of Hong Kong, Hong Kong SAR, China
}

\begin{abstract}
The present cross-sectional study aimed to assess daytime sleepiness in Chinese adolescents using the Paediatric Daytime Sleepiness Scale (PDSS) and to identify associations between PDSS answers and craniofacial characteristics. A group of 265 Chinese adolescents aged 11-17 years self-completed the PDSS, and their extra- and intra-oral craniofacial characteristics were recorded. Among the participants, 59.7\% (157) experienced one or more daytime sleepiness events. No significant associations were found between total PDSS scores and the craniofacial parameters, but when PDSS answers were assessed at the item level, several craniofacial characteristics were found to be positively associated with daytime sleepiness, such as hypertrophic tonsils $(P=0.05)$, a relatively large tongue $(\mathrm{P}<0.01)$, a bilateral Class II molar relationship $(\mathrm{P}<0.05)$ and increased overjet $(\mathrm{P}<0.05)$. A short lower face $(\mathrm{P}<0.01)$ and a convex profile $(\mathrm{P}<$ 0.01 ) were found to be negatively associated with daytime sleepiness. Daytime sleepiness is commonly reported among Chinese adolescents seeking orthodontic treatment and there are potential associations between the condition and craniofacial characteristics. An assessment of daytime sleepiness is recommended to orthodontists in young patients presenting with hypertrophic tonsils, relative large tongues and Class II tendency malocclusions, and appropriate medical referrals should also be considered.
\end{abstract}

Keywords: Adolescents, Chinese, craniofacial abnormalities, sleepiness.

\section{INTRODUCTION}

Daytime sleepiness is common in adolescents. According to a systematic analysis of sleep disturbance among 1,629 Hong Kong adolescents, the prevalence of excessive daytime sleepiness (EDS) was $41.9 \%$ [1]. A similar prevalence (41$42 \%$ ) was reported by a Canadian study based on a sample of 3,235 individuals [2]. Daytime sleepiness can have profound negative effects on the behavior [3], mood [4] and school performance of adolescents [5], and is increasingly becoming a concern.

The main cause of daytime sleepiness in adolescents is inadequate sleep [6], which is influenced by pubertal

*Address correspondence to this author at the Department of Paediatric Dentistry and Orthodontics, Faculty of Dentistry, the University of Hong Kong, Hong Kong SAR, China;

Tel: 00852-28590252, Fax: 00852-25593803; E-mail: yangyanq@hku.hk development [7]. As it is difficult to differentiate insufficient sleep from others causes of daytime sleepiness, such as sleep-disordered breathing (SDB), insomnia, narcolepsy, idiopathic hypersomnia, periodic limb movement during sleep, medication or caffeine intake [8], all causes of daytime sleepiness need to be investigated. Sleep-disordered breathing is experienced during sleep and is caused by prolonged partial obstruction or intermittent complete obstruction of the upper airway, and has been defined as obstructive sleep apnea syndrome (OSAS) with the addition of snoring [9].

Daytime sleepiness is a symptom of SDB, especially in adults with SDB, and was previously thought to be absent in most adolescents [10]. However, this point has been challenged using the gold-standard objective test for daytime sleepiness, i.e., the Multiple Sleep Latency Test (MSLT). Gozal et al. $[11,12]$ found that 13 to $20 \%$ of non-obese adolescents fulfilling the criteria for OSA displayed EDS. As a consensus opinion has not yet been reached $[9,13]$, the 


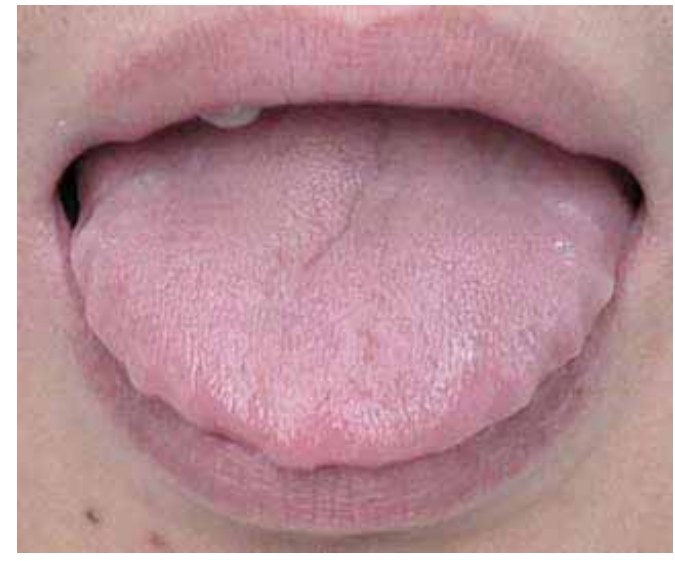

Fig. (1). Illustration of a relatively large tongue (see the imprints of the lateral margins of the tongue).

association between paediatric SDB and daytime sleepiness requires additional assessment.

It is hypothesized that if the association between paediatric SDB and daytime sleepiness is strong, then causes of SDB, such as adenotonsillar hypertrophy, obesity and craniofacial anomalies, may be correlated with daytime sleepiness. Adenotonsillar hypertrophy and obesity [14, 15] have been reported as being associated with daytime sleepiness in adolescents. However the question whether craniofacial anomalies are also directly associated with daytime sleepiness remains unanswered. To our knowledge, the present paper is the first paper attempting to associate craniofacial characteristics and daytime sleepiness in Chinese adolescents.

Huynh et al. [16] and Ikävalko et al. [17] have shown orthodontic clinical assessment could offer an important opportunity to evaluate the associate between SDB and craniofacial anomalies; however their samples were Caucasian subjects. In the present study, we utilized orthodontic clinical assessment to investigate the association between the craniofacial characteristics of Chinese adolescents and daytime sleepiness via clinical examination and the Pediatric Daytime Sleepiness Scale (PDSS) questionnaire [18].

\section{MATERIALS AND METHODS}

\section{Subjects}

A cross-sectional study was conducted at a university teaching hospital. The study was approved by the Institutional Review Board of the University of Hong Kong/Hospital Authority Hong Kong West Cluster (IRB Reference Number: UW 12-405). A sample of Chinese subjects aged 11-17 years seeking orthodontic treatment was recruited. Adolescents with craniofacial syndromes, cleft lips and/or palates or who were evidently overweight (according to their neck and waist circumferences) were excluded.

Based on a previous study [19], the required sample size of the logistic regression with every possible factor considered was at least 150 . Given an anticipated dropout rate of $20 \%, 188$ subjects was the minimum sample size.

\section{Data Collection}

All of the subjects self-completed a previously validated Chinese version of the eight-item Paediatric Daytime Sleepiness Scale (PDSS) [20]. The craniofacial assessment including several standard extra- and intra-oral examinations was conducted by one trained orthodontist (M.G.) and, in a pilot study, the assessment was calibrated with another experienced orthodontist (Y.Q.Y.).

An extra-oral assessment was performed with the subject sitting upright and in Natural Head Position (NHP), and included assessment of the profile and frontal views and the mandibular plane angle [21, 22] (Table 1).

The intra-oral soft tissue was evaluated according to the subject's tonsil size (according to the Brodsky grade) [23]; and relative tongue size (Fig. 1) [24] (Table 1).

The dentition was assessed according to the shape of the upper arch, and lower arch, the height of palatal vault, the molar relationship, the incisor relationship, the overbite [2527] and the amount of overjet (Table 1).

The subjects' basic demographics were also recorded, including age, sex and body mass index (BMI).

\section{DATA ANALYSIS}

Data are presented as the mean, standard deviation and range for the continuous variables and as percentages for the categorical variables. Cronbach's alpha was used to assess the internal consistency of the answers to the eight-item PDSS questions. The total PDSS scores were compared with continuous variables (age, BMI and overjet) using Spearman rank correlations; with the dichotomous variable (Insex) using the Mann-Whitney U-test and with the other multiple variables using Kruskal-Wallis one-way analysis of variance (ANOVA). Responses to the PDSS were also analyzed as percentages by combining the events "always or frequently" into "yes" and "sometimes, seldom and never" into "no" for each individual item. These data were compared with continuous variables (age, BMI and overjet) using the MannWhitney U-test and with categorical variables using the Pearson chi-square test. A binary logistic regression was calculated to assess the associations between each PDSS item and all of the variables. Statistical significance was set at a $P<0.05$. Statistical analyses were performed with SPSS software (IBM SPSS Statistics 20, IBM Corp.) (Fig. 2).

\section{RESULTS}

\section{Subject Profiles and PDSS Response Rate}

Of the subjects who sought orthodontic treatment during the 2012 screening sessions, 265 subjects (99 boys and 166 girls; mean age $13.7 \pm 1.9$ years) met the inclusive criteria and agreed to complete the questionnaire undergo a clinical examination. The subject profiles and response rates are presented in Tables $\mathbf{2}$ and $\mathbf{3}$.

The Cronbach's alpha of the PDSS was 0.7 , indicating satisfactory internal consistency. The PDSS scores ranged 

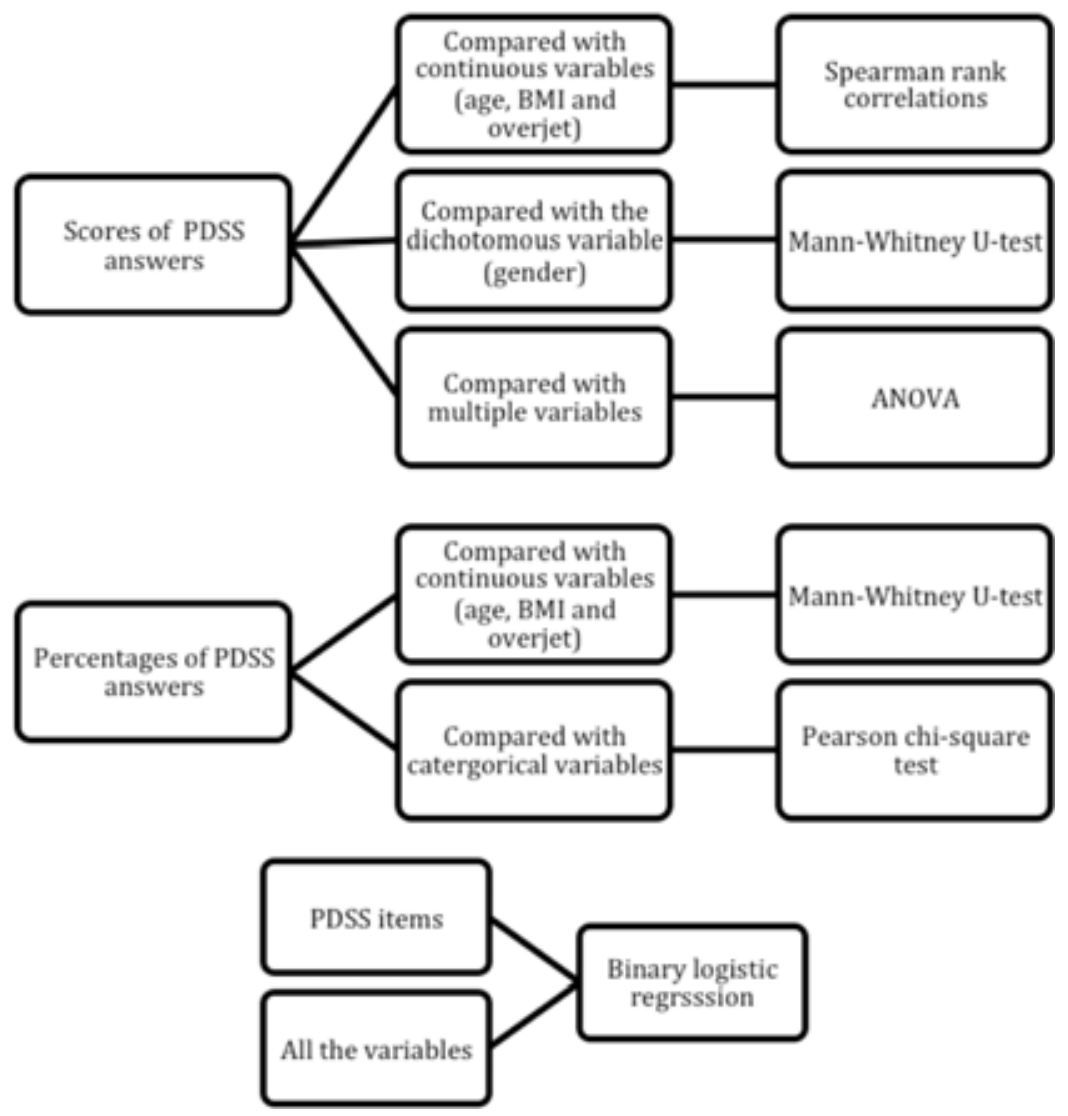

Fig. (2). Flowchart of statistical tests used in the present study Table 2. Profile of subjects recruited in the present study.

Table 1. Details of craniofacial assessment.

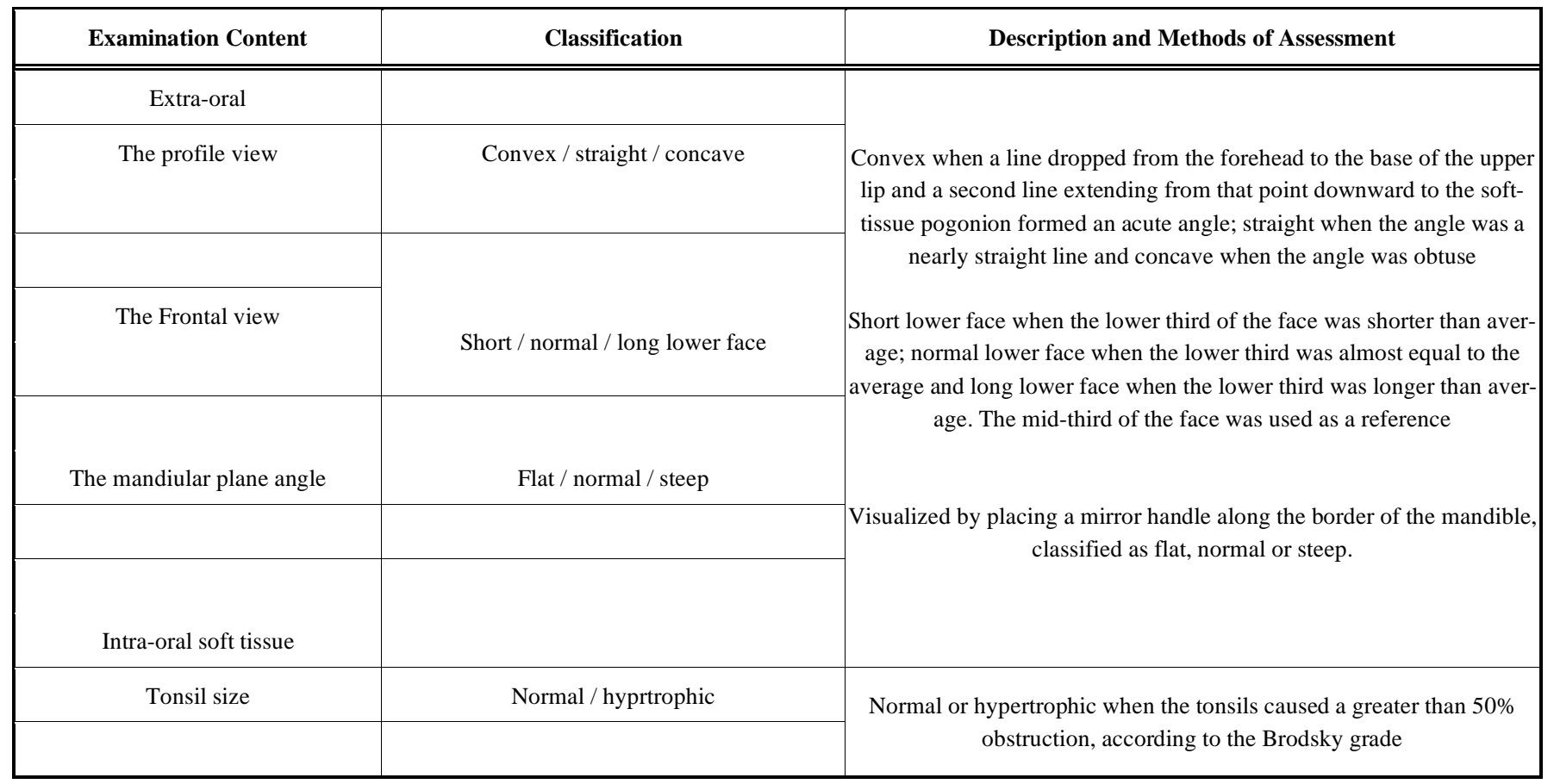


Table 1. contd...

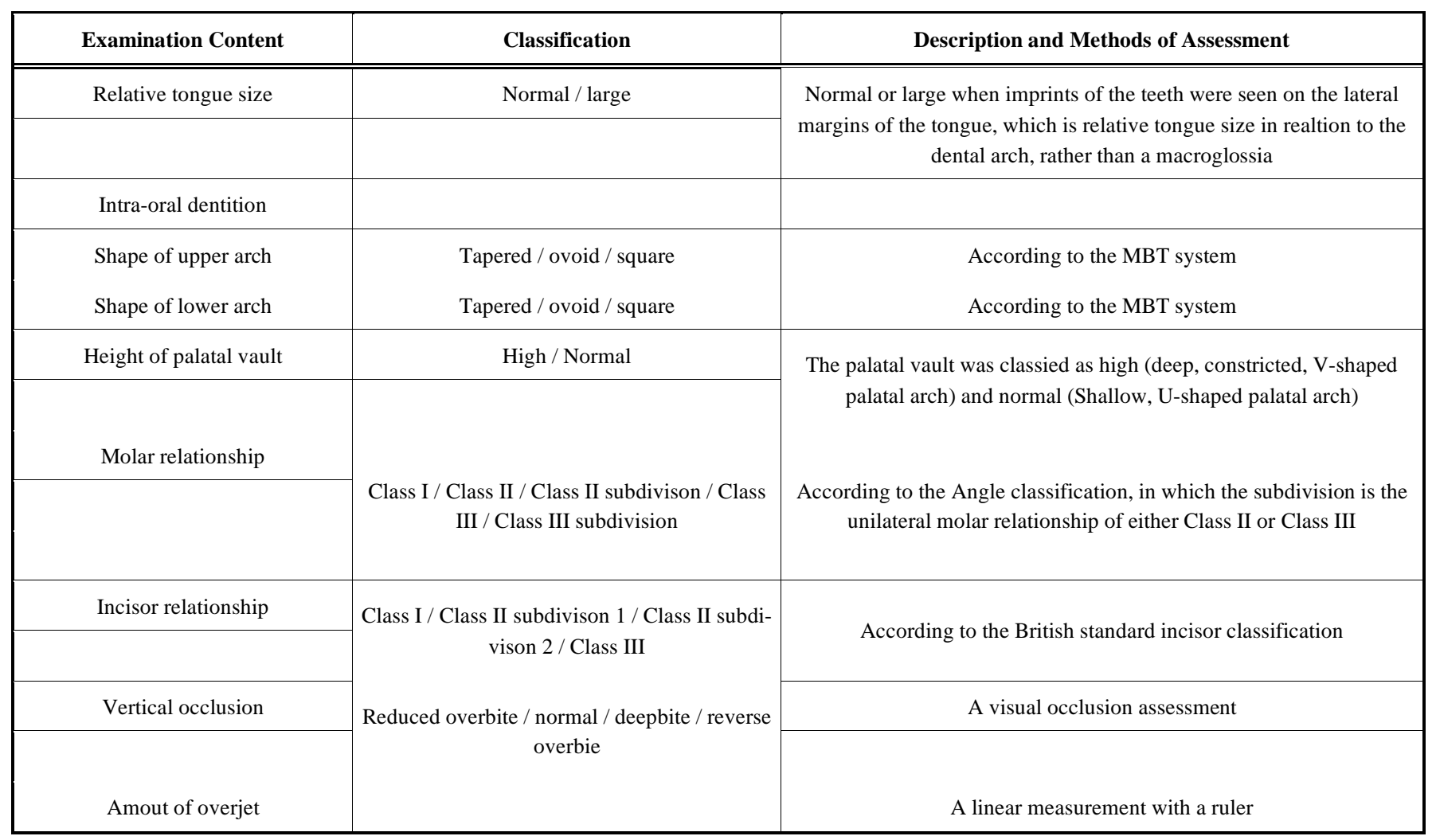

Table 2. Profile of subjects recruited in present study.

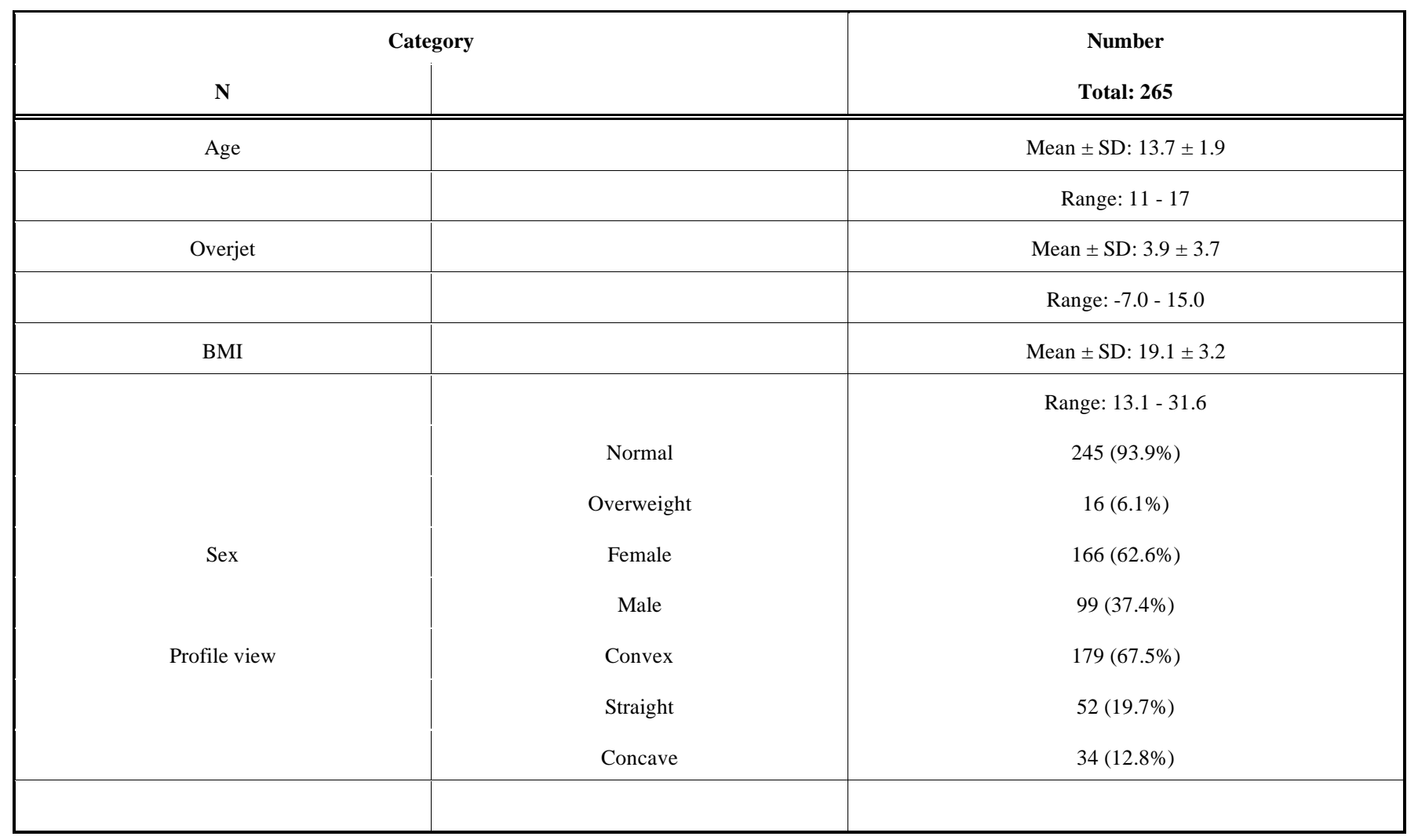


Table 2. contd...

\begin{tabular}{|c|c|c|}
\hline \multicolumn{2}{|c|}{ Category } & \multirow{2}{*}{$\begin{array}{c}\text { Number } \\
\text { Total: } 265\end{array}$} \\
\hline $\mathbf{N}$ & & \\
\hline \multirow[t]{3}{*}{ Frontal view } & Short lower face & $54(20.4 \%)$ \\
\hline & Normal lower face & $140(52.8 \%)$ \\
\hline & Long lower face & $71(26.8 \%)$ \\
\hline \multirow[t]{3}{*}{ Mandibular angle } & Flat & $43(16.2 \%)$ \\
\hline & Normal & $125(47.2 \%)$ \\
\hline & Steep & $97(36.6 \%)$ \\
\hline \multirow[t]{2}{*}{ Tonsil size } & Normal & $244(92.8 \%)$ \\
\hline & Hypertrophic & $19(7.2 \%)$ \\
\hline \multirow[t]{2}{*}{ Relative tongue size } & Normal & $241(91.6 \%)$ \\
\hline & Large & $22(8.4 \%)$ \\
\hline \multirow[t]{3}{*}{ Shape of upper arch } & Tapered & $36(13.6 \%)$ \\
\hline & Ovoid & $175(66.3 \%)$ \\
\hline & Square & $53(20.1 \%)$ \\
\hline \multirow[t]{3}{*}{ Shape of lower arch } & Tapered & $40(15.1 \%)$ \\
\hline & Ovoid & $184(69.4 \%)$ \\
\hline & Square & $41(15.5 \%)$ \\
\hline \multirow[t]{2}{*}{ Height of palatal vault } & High & $55(21.1 \%)$ \\
\hline & Normal & $206(78.8 \%)$ \\
\hline \multirow[t]{3}{*}{ Molar relationship } & Class I & $95(35.9 \%)$ \\
\hline & ClassII & $59(22.3 \%)$ \\
\hline & ClassII subdivision & $43(16.2 \%)$ \\
\hline \multirow{6}{*}{ Incisor relationship } & ClassIII & $39(14.7 \%)$ \\
\hline & ClassIII subdivision & $29(10.9 \%)$ \\
\hline & ClassI & $73(28.3 \%)$ \\
\hline & ClassII division 1 & $121(46.9 \%)$ \\
\hline & ClassII division2 & $13(5.0 \%)$ \\
\hline & ClassIII & $51(19.8 \%)$ \\
\hline \multirow[t]{4}{*}{ Vertical occlusion } & Reduced overbite & $28(10.8 \%)$ \\
\hline & Normal & $115(44.4 \%)$ \\
\hline & Deepbite & $85(32.8 \%)$ \\
\hline & Reverse overbite & $31(12 \%)$ \\
\hline
\end{tabular}


Table 3. Responses to the PDSS questions.

\begin{tabular}{|c|c|c|}
\hline & Events "sometimes/seldom/never" & Events "always/frequently" \\
\hline PDSS score & \multicolumn{2}{|c|}{ Mean \pm SD: $12.2 \pm 4.5$} \\
\hline Sum answers of Q1-Q8 & $106(40.3 \%)$ & $157(59.7 \%)$ \\
\hline Answer to Q1: "fall asleep or get drowsy during class periods" & $240(90.6 \%)$ & $25(9.4 \%)$ \\
\hline *Answer to Q3: "usually alert most of the day" & $16(6.0 \%)$ & $249(94.0 \%)$ \\
\hline Answer to Q4: "ever tired and grumpy during the day" & $236(89.4 \%)$ & $28(10.6 \%)$ \\
\hline Answer to Q5: "have trouble getting out tobed in the morning" & $215(81.1 \%)$ & $50(18.9 \%)$ \\
\hline Answer to Q8: "you need more sleep" & $180(67.9 \%)$ & $85(36.4 \%)$ \\
\hline
\end{tabular}

*The events of daytime sleepiness should be reversed for the answer to Q3.

Table 4. Statistical association between the frontal view and PDSS answers.

\begin{tabular}{|c|c|c|c|c|}
\hline \multicolumn{2}{|c|}{ PDSS item } & Convex Profile $(67.5 \%)$ & Concave and Staight Profile (32.5\%) & $P$ value \\
\hline PDSS answer to Q1 & Events "sometimes/seldom/never" & $168(93.9 \%)$ & $72(83.7 \%)$ & \\
\hline \multirow[t]{2}{*}{ PDSS answer to Q4 } & Events "sometimes/seldom/never" & $165(92.2 \%)$ & $71(83.5 \%)$ & \\
\hline & Events "always/frequently" & $14(7.8 \%)$ & $14(16.8 \%)$ & $0.033^{*}$ \\
\hline
\end{tabular}

$* \mathrm{P}<0.05 ; * * \mathrm{P}<0.01$

Table 5. Statistical association between the profile view and PDSS answers.

\begin{tabular}{|c|c|c|c|c|}
\hline \multicolumn{2}{|c|}{ PDSS item } & Short lower face $(20.4 \%)$ & Normal and Long Lower Face (79.6\%) & $P$ value \\
\hline PDSS answer to Q7 & Events "sometimes/seldom/never" & $41(75.9 \%)$ & $127(60.5 \%)$ & \\
\hline
\end{tabular}

$* \mathrm{P}<0.05 ;$

from 0 to 28 (mean $\pm \mathrm{SD}, 12.2 \pm 4.5)$. Though the reported daytime sleepiness events for each individual item were considerably low, the sum of the items showed that $59.7 \%$ of the subjects reported "yes" for the daytime sleepiness event.

\section{Association Between the PDSS and Craniofacial Vari- ables}

The statistical analysis showed no significant associations between the total PDSS scores and the craniofacial variables. In the evaluation of the PDSS answers as categorical data at the item level, chi-square analysis showed that the subjects classified as having a convex profile $(P=0.008$ for Q1 and $P=0.033$ for Q4) (Table 4) or a short lower face $(P$ $=0.035$ for Q7) (Table 5) experienced less daytime sleepiness than the other subjects. In contrast, subjects with a relatively large tongue $(P=0.001$ in Q5) (Table 6) and a bilateral Class II molar relationship $(P=0.006$ in Q6) (Table 7) experienced more daytime sleepiness than the other subjects. In addition, the Mann-Whitney U-test showed more daytime sleepiness was associated with a larger overjet $(P=0.037$ for Q6, $5.1 \pm 5.7$ vs. $3.7 \pm 3.6 \mathrm{~mm}$ ) (Table 8). Although a statistical association between age $(P=0.008$ in Q7) and daytime 
Table 6. Statistical association between the relative tongue size and PDSS answers.

\begin{tabular}{|c|c|c|c|c|}
\hline \multicolumn{2}{|c|}{ PDSS item } & Small and normal tongue (91.6\%) & Large tongue (8.4\%) & $\boldsymbol{P}$ value \\
\hline \hline PDSS answer to Q5 & Events "sometimes/seldom/never" & $201(83.4 \%)$ & $12(54.5 \%)$ \\
\hline & Events "always/frequently" & $40(16.6 \%)$ & $10(45.5 \%)$ \\
\hline
\end{tabular}

$* * * \mathrm{P}<0.001$

Table 7. Statistical association between the molar relationships and PDSS answers.

\begin{tabular}{|c|c|c|c|c|}
\hline \multicolumn{2}{|c|}{ PDSS item } & Other Molar Relationships (77.7\%) & Class II molar (22.3\%) & P value \\
\hline \hline PDSS answer to Q6 & Events "sometimes/seldom/never" & $192(91.4 \%)$ & $43(78.2 \%)$ & $12(21.8 \%)$ \\
\hline & Events "always/frequently" & $18(6.8 \%)$ & $0.006^{* *}$ \\
\hline
\end{tabular}

$* * \mathrm{P}<0.01$

Table 8. Statistical association between the overjet and PDSS answers.

\begin{tabular}{|c|c|c|c|}
\hline \multicolumn{2}{|c|}{ PDSS item } & Overjet (Mean \pm SD) & P value \\
\hline \hline PDSS answer to Q6 & Events "sometimes/seldom/never" & $3.7 \pm 3.6$ \\
& Events "always/frequently" & $5.1 \pm 3.7$ \\
\hline
\end{tabular}

$* \mathrm{P}<0.05 ;$

Table 9. Association between craniofacial variables and PDSS answers shown by binary logistic regression.

\begin{tabular}{|c|c|c|c|c|c|}
\hline & B & S.E. & OR & OR $(95 \% \mathrm{CI})$ & $P$ value \\
\hline Q1: Straight or concave profile $v s$. convex profile & 1.0 & 0.4 & 2.7 & $1.2-6.4$ & $0.018^{*}$ \\
\hline Q5: Hypertrophy tonsil size $v s$. normal & 1.1 & 0.6 & 3.0 & $1.0-9.0$ & $0.050^{*}$ \\
\hline Q5: Large tongue size $v s$. normal & 1.8 & 0.5 & 5.9 & $2.2-15.6$ & $<0.001 * * *$ \\
\hline Q7: Younger age vs. older & 0.3 & 0.1 & 1.3 & $1.1-1.5$ & $0.001 * * *$ \\
\hline Q7: Normal and long lower face $v s$. short lower face & 0.9 & 0.4 & 2.6 & $1.2-5.3$ & $0.011^{*}$ \\
\hline Q8: Large tongue size $v s$. normal & 1.0 & 0.5 & 2.7 & $1.0-6.8$ & $0.043^{*}$ \\
\hline
\end{tabular}

$* \mathrm{P}<0.05 ; * * * \mathrm{P}<0.001$

B: estimated logit coefficient; S.E.: standard error of the coefficient; OR: odds ratio; CI: confidence interval.

sleepiness events was also shown by Mann-Whitney U-test, the actual age difference was very minimal (13.9 \pm 2.0 vs. $13.3 \pm 1.9$ years). Binary logistic regression analysis showed similar results, in which hypertrophic tonsils, a relatively large tongue and a bilateral Class II molar relationship were positively associated with daytime sleepiness, and that a short lower face, convex profile and age were negatively associated with daytime sleepiness (Table 9).

\section{DISCUSSION}

\section{The Rationale of the Present Study}

To associate daytime sleepiness with craniofacial anomalies, it would have been optimal to assess the former using the gold-standard objective test (i.e., the MSLT) and the latter using a lateral cephalogram or three-dimensional image 
analysis (CT or MRI). However, in the case of our orthodontic screening subjects, it was not possible to diagnose daytime sleepiness using the MSLT due to time and cost limitations, and for ethical reasons, no radiographs were taken.

The use of questionnaires to identify daytime sleepiness in adolescents with suspected SDB was found to be effective. Chervin et al. [14] reported that subjective sleepiness can be elicited by the Paediatric Sleep Questionnaire (PSQ), and the validity of their findings was verified by the MSLT. Melendres et al. [28] found that adolescents with suspected SDB showed more daytime sleepiness than control subjects according to the modified Epworth Sleepiness Scale (ESS), and the ESS was found to be correlated with the polysomnographic parameters. Drake et al. [18] reported the PDSS was suitable for the assessment of daytime sleepiness for middleschool-age adolescents, and its Chinese version which was used in the present study, was also reported as a reliable and valid tool for the measurement of sleepiness and for the screening for more severe pathological sleepiness, such as narcoplepsy [20].

The PDSS was chosen in the present study because the adolescent subjects were in the middle-school-age, and the self-completed questionnaire was considered to be more precise than a parent-reported questionnaire [29]. The limitations of PDSS were its lack of validation against the MSLT, and in the present study, its validity was not compared to the other parent-reported or teacher-reported questionnaires.

The most common cause of daytime sleepiness in adolescents is insufficient sleep, which is affected by pubertal development [7]. Previous studies have shown that pubertal development is associated with an increase in daytime sleepiness and post-pubertal adolescents may need more sleep to maintain pre-pubertal levels of daytime alertness $[30,31]$. Therefore the direct association between daytime sleepiness and craniofacial anomalies is likely to be subtle. The present study used the score-based and item-based methods to perform the analysis. Another commonly used questionnaire (PSQ) was also applied via either a scorebased or item-based analysis [14, 15]. As the value of the Cronbach's alpha in the present study showed satisfactory internal consistency (0.7), the item-based analysis was considered reliable.

\section{The Prevalence of Daytime Sleepiness Found in the Pre- sent Study}

The present study showed that, although reported daytime sleepiness events were not frequent for the individual questions (from $6 \%$ to $36.4 \%$ ), a high incidence of events $(59.7 \%)$ was found for the summed items. This indicated that a high proportion of Chinese adolescents seeking orthodontic treatment were experiencing one or more daytime sleepiness events. This number $(59.7 \%)$ was higher than the reported prevalence of daytime sleepiness $(41.9 \%)$ of the general adolescent population in Hong Kong [1], implying that adolescents with craniofacial anomalies or malocclusion are experiencing more daytime sleepiness than the general population. Although this conclusion was not based on rigorous investigation, it reflected a trend. Since the 265 subjects were selected from the only teaching/public dental hospital in Hong Kong and the screening clinics were conducted for a year (2012), they could be considered to represent the total Chinese adolescent orthodontic population.

\section{The Association Between Craniofacial Characteristics and Daytime Sleepiness}

When PDSS responses were assessed at the item level, several craniofacial features were found to be associated with daytime sleepiness. Hypertrophic tonsils and a relatively large tongue were associated with a high risk of daytime sleepiness and a Class II tendency including increased overjet and a bilateral Class II molar relationship was also positively related. Adolescents with a short lower face and convex profile were found to be at low risk of daytime sleepiness. However it should be appreciated that the bilateral class II molar relationship may not be indicative of the under lying skeletal pattern due to early loss of deciduous teeth and molar drifting.

Hypertrophy of the tonsils and adenoids is a widely acknowledged high risk factor for SDB $[32,33]$. Although the size of the tonsils of this adolescent population (aged 11-17 years) should have begun to reduce from their maximum size during the pre-pubertal years, the results show that hypertrophic tonsils were found to be associated with a high risk of daytime sleepiness.

The present study found a relatively large tongue size was associated with daytime sleepiness, however Arens et al. [34] reported a similar tongue size of children suffering from OSAS and a normal control group. This difference may be explained by age, as the mean age of the subjects in the study by Arens et al. was 4.8 years, compared with 13.7 years in the present study. Considering that tongue size is a confirmed risk factor for adult OSAS $[35,36]$, this may imply that the tongue is associated with the daytime sleepiness as a result of increasing age.

As no previous study has focused on the association between craniofacial characteristics and daytime sleepiness, the results of the present study could only be compared with the relationship between craniofacial characteristics and SDB.

It was found that a Class II tendency, including increased overjet and a bilateral Class II molar relationship, was associated with daytime sleepiness. A similar study based on dental models also reported an association between increased overjet, Class II molar relationship and SDB [37]. Two other recent meta-analyses also have reported a relationship between a Class II tendency and paediatric SDB [38, 39]. Flores-Mir et al. [38] identified that the SNB and ANB angles in children with OSAS had statistically significant differences in comparison with those in a control group. Katyal et al. [39] found that children with OSAS and primary snoring showed increases of $1.64^{\circ}$ and $1.54^{\circ}$ in the ANB angle compared with the controls, respectively.

According to the result of the present study, the unilateral Class II molar relationship (e.g., Class II subdivision) may not have the same association as the bilateral molar relationship; because the unilateral Class II molar relationship is 
caused by the mesial migration of an upper molar in a Class I skeletal base rather an actual Class II skeletal relationship.

Two similar studies reported an association between the profile and SDB. Huynh et al. [16] reported that a dolichofacial (long face) is related to SDB. Although the present study did not find subjects with a long lower face to be at risk of daytime sleepiness, subjects with a short lower face were found to be at low risk of daytime sleepiness. Ikävalko et al. [17] reported that a convex profile was a high risk factor for SDB. On the contrary, the present study found a convex profile was at lower risk of daytime sleepiness compared with those with a concave or a straight profile. Possible reasons include differences in age of the subjects; 6-8 years old compared with 11-17 years old in the present study and secondly, ethnicity. Compared with Caucasians, more Chinese people with a convex profile have a Class I occlusion rather than Class II [40].

The associations between daytime sleepiness and the three demographic variables examined (age, sex and BMI) were also analyzed via binary logistic regression. Since obesity was a confounding factor, obviously overweight subjects were excluded. Only $16(6.1 \%)$ subjects were classified as overweight according to the BMI cutoff score of the International Obesity Task Force [41], and no association was found between daytime sleepiness and BMI in the study population. Furthermore, no association was found between daytime sleepiness and sex in the present study. Carskadon et al. [30] also reported no sex difference between pubertal subjects with daytime sleepiness. However, greater daytime sleepiness was found in older subjects, which was not confirmed by the present study.

\section{The Implications to Orthodontists}

In the present study, when the PDSS answers were analyzed along with the scores, no associations were found. Thus, we believe that the craniofacial parameters investigated in this study are only potentially associated with daytime sleepiness, and further studies are required. Although the present study focused on Chinese adolescents, a similar association between craniofacial anomalies and SDB was reported for Caucasian adolescents. Therefore in order to decrease the potential impact of daytime sleepiness on adolescents' health, an assessment of daytime sleepiness is recommended to orthodontists when examining young patients presenting with hypertrophic tonsils, relatively large tongues and Class II tendency malocclusions. Appropriate medical referrals should also be considered.

\section{CONCLUSION}

Daytime sleepiness is commonly reported among Chinese adolescents seeking orthodontic treatment. A relatively large tongue, hypertrophic tonsils and a Class II tendency (including increased overjet and a bilateral Class II molar relationship) are potential contributing factors to daytime sleepiness. An assessment for daytime sleepiness is recommended to orthodontists in this group of patients.

\section{CONFLICT OF INTEREST}

The authors declare that this study was funded by the research funding of the University of Hong Kong, and we have no financial and non-financial competing interest.

\section{ACKNOWLEDGEMENTS}

The authors sincerely thank Kar Yan Li for statistical assistance and Yu-Shu Huang (Chang Gung Memorial University Hospital, Taipei) and Daniel K. Ng (Kwong Wah Hospital, Hong Kong SAR) for kindly providing the Chinese version of the PDSS.

\section{REFERENCES}

[1] Chung KF, Cheung MM. Sleep-wake patterns and sleep disturbance among Hong Kong Chinese adolescents. Sleep 2008; 31(2):185-94.

[2] Gibson ES, Powles AC, Thabane L, et al. "Sleepiness" is serious in adolescence: Two surveys of 3235 Canadian students. BMC Pub Health 2006; 6: 116.

[3] Golan N, Shahar E, Ravid S, Pillar G. Sleep disorders and daytime sleepiness in children with attention-deficit/hyperactive disorder. Sleep 2004; 27(2): 261-6.

[4] Morrison DN, McGee R, Stanton WR. Sleep problems in adolescence. J Am Acad Child Adol Psychiat 1992; 31(1): 94-9.

[5] Wolfson AR, Carskadon MA. Understanding adolescents' sleep patterns and school performance: A critical appraisal. Sleep Med Rev 2003; 7(6): 491-506.

[6] Fallone G, Acebo C, Seifer R, Carskadon MA. Experimental restriction of sleep opportunity in children: Effects on teacher ratings. Sleep 2005; 28(12): 1561-7.

[7] Fallone G, Owens JA, Deane J. Sleepiness in children and adolescents: Clinical implications. Sleep Med Rev 2002; 6(4): 287306.

[8] Millman RP. Working group on sleepiness in adolescents/young A, adolescence AAPCo: Excessive sleepiness in adolescents and young adults: Causes, consequences, and treatment strategies. Pediatrics 2005; 115(6): 1774-86.

[9] Marcus CL, Brooks LJ, Draper KA, et al. Diagnosis and management of childhood obstructive sleep apnea syndrome. Pediatrics 2012;130(3): e714-55.

[10] Carroll JL. Obstructive sleep-disordered breathing in children: New controversies, new directions. Clin Chest Med 2003; 24(2): 261-82.

[11] Gozal D, Wang M, Pope DW, Jr. Objective sleepiness measures in pediatric obstructive sleep apnea. Pediatrics 2001; 108(3): 693-7.

[12] Gozal D, Serpero LD, Kheirandish-Gozal L, Capdevila OS, Khalyfa A, Tauman R. Sleep measures and morning plasma TNFalpha levels in children with sleep-disordered breathing. Sleep 2010; 33(3): 319-25.

[13] Marcus CL, Brooks LJ, Draper KA, et al. Diagnosis and management of childhood obstructive sleep apnea syndrome. Pediatrics 2012; 130(3): 576-84.

[14] Chervin RD, Weatherly RA, Ruzicka DL, et al. Subjective sleepiness and polysomnographic correlates in children scheduled for adenotonsillectomy vs other surgical care. Sleep 2006; 29(4): 495-503.

[15] Tsaoussoglou M, Bixler EO, Calhoun S, Chrousos GP, Sauder K, Vgontzas AN. Sleep-disordered breathing in obese children is associated with prevalent excessive daytime sleepiness, inflammation, and metabolic abnormalities. J Clin Endocrinol Metab 2010; 95(1): 143-50.

[16] Huynh NT, Morton PD, Rompre PH, Papadakis A, Remise C. Associations between sleep-disordered breathing symptoms and facial and dental morphometry, assessed with screening examinations. Am J Orthod Dentofacial Orthop 2011; 140(6): 76270.

[17] Ikavalko $\mathrm{T}$, Tuomilehto $\mathrm{H}$, Pahkala $\mathrm{R}$, et al. Craniofacial morphology but not excess body fat is associated with risk of having sleep-disordered breathing--the PANIC study (a 
questionnaire-based inquiry in 6-8-year-olds). Eur J Pediatr 2012; 171(12): 1747-52.

[18] Drake C, Nickel C, Burduvali E, Roth T, Jefferson C, Pietro B. The pediatric daytime sleepiness scale (PDSS): Sleep habits and school outcomes in middle-school children. Sleep 2003; 26(4): 455-8.

[19] Peduzzi P, Concato J, Kemper E, Holford TR, Feinstein AR. A simulation study of the number of events per variable in logistic regression analysis. J Clin Epidemiol 1996; 49(12): 1373-9.

[20] Yang CM, Huang YS, Song YC. Clinical utility of the Chinese version of the pediatric daytime sleepiness scale in children with obstructive sleep apnea syndrome and narcolepsy. Psychiat Clin Neurosci 2010; 64(2): 134-40.

[21] Thomas M. Graber RLVJ, Vig KWL. Orthodontics: Present principles \& techniques, $4^{\text {th }}$ ed. St. Louis: Elsev Mosby 2005.

[22] William R. Proffit HWF, David M. Sarver: Contemporary orthodontics, $5^{\text {th }}$ ed. St. Louis: Elsev Mosby 2013.

[23] Brodsky L. Modern assessment of tonsils and adenoids. Pediatr Clin North Am 1989; 36(6): 1551-69.

[24] Thomas Rakosi IJ, Thomas M. Graber: Color atlas of dental medicine orthodontic-diagnosis. New York: Thieme medical publishers Inc 1993.

[25] McLaughlin RP, Bennett JC, Trevisi HJ. Systemized orthodontic treatment mechanics. St. Louis: Elsevier Mosby 2001.

[26] Galvez J, Methenitou S. Airway obstruction, palatal vault formation and malocclusion: A cross-sectional study. J Pedodont 1989; 13(2): 133-40.

[27] Thilander B, Rönning O. Introduction to orthodontics, $2^{\text {nd }}$ ed. Stockholm: Gothia 1995.

[28] Melendres MC, Lutz JM, Rubin ED, Marcus CL. Daytime sleepiness and hyperactivity in children with suspected sleepdisordered breathing. Pediatrics 2004; 114(3): 768-75.

[29] Hoban TF, Chervin RD. Assessment of sleepiness in children. Semin Pediatr Neurol 2001; 8(4): 216-28.

[30] Carskadon MA, Harvey K, Duke P, Anders TF, Litt IF, Dement WC. Pubertal changes in daytime sleepiness. Sleep 1980; 2(4): 453-60.
[31] Sadeh A, Raviv A, Gruber R. Sleep patterns and sleep disruptions in school-age children. Dev Psychol 2000; 36(3): 291-301.

[32] Brodsky L, Adler E, Stanievich JF. Naso- and oropharyngeal dimensions in children with obstructive sleep apnea. Int J Pediatr Otorhinolaryngol 1989; 17(1): 1-11.

[33] Fregosi RF, Quan SF, Kaemingk KL, et al. Sleep-disordered breathing, pharyngeal size and soft tissue anatomy in children. J Appl Physiol 2003; 95(5): 2030-8.

[34] Arens R, McDonough JM, Costarino AT, et al. Magnetic resonance imaging of the upper airway structure of children with obstructive sleep apnea syndrome. Am J Respir Crit Care Med 2001; 164(4): 698-703.

[35] Do KL, Ferreyra H, Healy JF, Davidson TM. Does tongue size differ between patients with and without sleep-disordered breathing? Laryngoscope 2000; 110(9): 1552-5.

[36] Lowe AA, Gionhaku N, Takeuchi K, Fleetham JA. Threedimensional CT reconstructions of tongue and airway in adult subjects with obstructive sleep apnea. Am J Orthod Dentofacial Orthop 1986; 90(5): 364-74.

[37] Pirila-Parkkinen K, Pirttiniemi P, Nieminen P, Tolonen U, Pelttari U, Lopponen H. Dental arch morphology in children with sleepdisordered breathing. Eur J Orthod 2009; 31(2): 160-7.

[38] Flores-Mir C, Korayem M, Heo G, Witmans M, Major MP, Major PW. Craniofacial morphological characteristics in children with obstructive sleep apnea syndrome: A systematic review and metaanalysis. J Am Dent Assoc 2013; 144(3): 269-77.

[39] Katyal V, Pamula Y, Martin AJ, Daynes CN, Kennedy JD, Sampson WJ. Craniofacial and upper airway morphology in pediatric sleep-disordered breathing: Systematic review and metaanalysis. Am J Orthod Dentofacial Orthop 2013; 143(1): 20-30 e23.

[40] Chiu CS, Clark RK. The facial soft tissue profile of the southern Chinese: Prosthodontic considerations. J Prosthet Dent 1992; 68(5): 839-50.

[41] Cole TJ, Bellizzi MC, Flegal KM, Dietz WH. Establishing a standard definition for child overweight and obesity worldwide: International survey. BMJ 2000; 320(7244): 1240-3.

Received: October 08, 2014

Revised: November 10, 2014

Accepted: November 27, 2014

(C) Gu et al.; Licensee Bentham Open.

This is an open access article licensed under the terms of the Creative Commons Attribution Non-Commercial License (http://creativecommons.org/licenses/by-nc/3.0/) which permits unrestricted, non-commercial use, distribution and reproduction in any medium, provided the work is properly cited. 